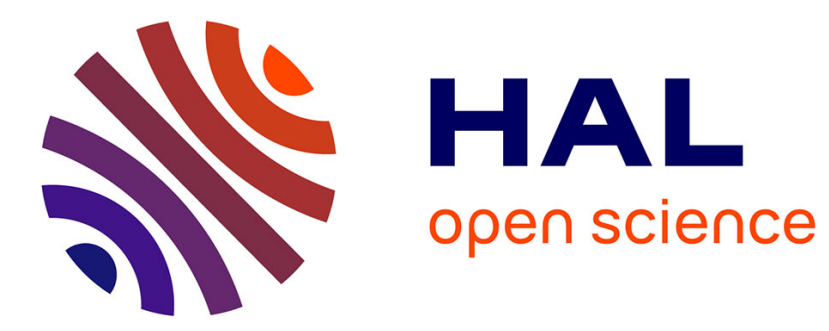

\title{
Magnetic anisotropy switching induced by shape memory effect in $\mathrm{NiTi} / \mathrm{Ni}$ bilayer
}

\author{
A. Kyianytsia, M. Ponçot, A. Letoffe, P. Boulet, S. Migot, J. Ghanbaja, I. \\ Cinar, R. Lima de Miranda, C. Bechtold, B. Kierren, et al.
}

\section{- To cite this version:}

A. Kyianytsia, M. Ponçot, A. Letoffe, P. Boulet, S. Migot, et al.. Magnetic anisotropy switching induced by shape memory effect in NiTi/Ni bilayer. Applied Physics Letters, 2019, 115 (22), pp.222402. 10.1063/1.5129893 . hal-02444214

\section{HAL Id: hal-02444214 \\ https://hal.science/hal-02444214}

Submitted on 17 Jan 2020

HAL is a multi-disciplinary open access archive for the deposit and dissemination of scientific research documents, whether they are published or not. The documents may come from teaching and research institutions in France or abroad, or from public or private research centers.
L'archive ouverte pluridisciplinaire HAL, est destinée au dépôt et à la diffusion de documents scientifiques de niveau recherche, publiés ou non, émanant des établissements d'enseignement et de recherche français ou étrangers, des laboratoires publics ou privés. 


\section{Magnetic anisotropy switching induced by shape memory effect in NiTi/Ni bilayer}

Cite as: Appl. Phys. Lett. 115, 222402 (2019); https://doi.org/10.1063/1.5129893

Submitted: 02 October 2019 . Accepted: 09 November 2019. Published Online: 25 November 2019

A. Kyianytsia, M. Ponçot, A. Letoffe, P. Boulet (D), S. Migot, J. Chanbaja, I. Cinar, R. Lima de Miranda, C. Bechtold, B. Kierren, O. Ozatay, and T. Hauet (D)

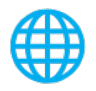

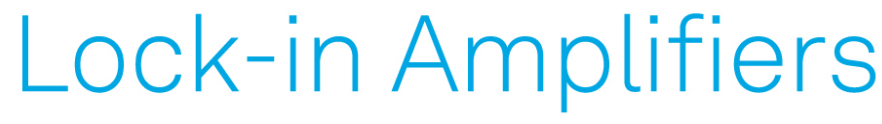

... and more, from DC to $600 \mathrm{MHz}$

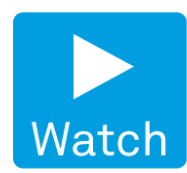




\title{
Magnetic anisotropy switching induced by shape memory effect in NiTi/Ni bilayer
}

\author{
Cite as: Appl. Phys. Lett. 115, 222402 (2019); doi: 10.1063/1.5129893 \\ Submitted: 2 October 2019 - Accepted: 9 November 2019 . \\ Published Online: 25 November 2019
}

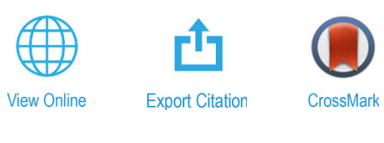

A. Kyianytsia, ${ }^{1,2}$ M. Ponçot, ${ }^{1}$ A. Letoffe, ${ }^{1}$ P. Boulet, ${ }^{1}$ iD S. Migot, ${ }^{1}$ J. Ghanbaja, ${ }^{1}$ I. Cinar, ${ }^{1,3}$ R. Lima de Miranda,
C. Bechtold, ${ }^{4}$ B. Kierren, O. Ozatay, ${ }^{4}$ and T. Hauet ${ }^{1, a)}$ (iD

\author{
AFFILIATIONS \\ ${ }^{1}$ Institut Jean Lamour, Université de Lorraine-CNRS, Nancy 54011, France \\ ${ }^{2}$ CRYOSCAN SAS, Nancy 54011, France \\ ${ }^{3}$ Department of Medical Imaging Techniques, Karamanoglu Mehmetbey University, Karaman 70100, Turkey \\ ${ }^{4}$ Acquandas $\mathrm{GmbH}$, Kiel 24143, Germany \\ ${ }^{5}$ Physics Department, Bogazici University, Bebek, Istanbul 34342, Turkey \\ a) thomas.hauet@univ-lorraine.fr
}

\begin{abstract}
Strain modulation during a two-way shape memory effect (TWSME) in a sputtered nitinol NiTi is used to reliably induce and switch by $90^{\circ}$ a uniaxial magnetic anisotropy of a $20 \mathrm{~nm}$ thick Ni film during the thermal cycle from $300 \mathrm{~K}$ to $400 \mathrm{~K}$. NiTi strain and its distribution are carefully measured by digital image correlation during tensile prestrain and subsequent temperature cycles in order to compare with Ni strain extracted from the magnetometry measurement and from transmission electron microscopy. In a NiTi/Ni bilayer, a variation of $2.7 \%$ strain in NiTi during the TWSME generates $1.3 \%$ strain in Ni, which results in a transition from $-2 \times 10^{4} \mathrm{~J} / \mathrm{m}^{3}$ in-plane magnetic anisotropy to $+1 \times 10^{5} \mathrm{~J} / \mathrm{m}^{3}$. Such a composite system offers a way to timely ease writability while maintaining high thermal stability at rest in magnetic media.
\end{abstract}

Published under license by AIP Publishing. https://doi.org/10.1063/1.5129893

\begin{abstract}
Many existing or promising technologies rely on controlling the magnetization direction of a ferromagnet: magnetic recording (hard disk drive and magnetic random access memory), sensors, quantum computing, etc. These technologies mostly use magnetic field, polarized current, spin current, heat, or polarized light as external excitation sources to orient the magnetic moment. In the ferromagnet itself, magnetic anisotropy is the key parameter to ensure the stability of magnetization direction at rest, but it also limits the reorientation of the magnetization by an external excitation. In the last decade, a huge amount of work has been devoted to constructing a composite system where magnetic anisotropy becomes tunable by coupling the ferromagnet to a functionalized layer. Electrical control of interfacial anisotropy with an insulator like $\mathrm{MgO}^{1}$ and interfacial strain transferred from an electrically controlled piezoelectric ${ }^{2}$ or ferroelectric ${ }^{3}$ material are still heavily pursued.

In 2016, Feng et al. ${ }^{4,5}$ proposed a novel approach to manipulate magnetic anisotropy by interfacial strain transferred from a thermally controlled NiTiNb shape memory alloy (SMA). They obtained pioneering results in showing small variation of interfacial anisotropy in $\mathrm{NiTiNb}(0.5 \mathrm{~mm}) / \mathrm{FePt}(10-20 \mathrm{~nm})$ and NiTiNb $(0.5 \mathrm{~mm}) / \mathrm{Fe}(2-5 \mathrm{~nm})$
\end{abstract}

both with in-plane anisotropy. This innovative architecture benefits from the shape memory effect, in particular, from the two-way shape memory effect (TWSME). The TWSME consists in a reproducible hysteretic transformation of shape memory alloys from a strained B19' structure (at low temperature) to a differently strained B2 structure (at high temperature) during the thermal cycle. NiTi-based alloys are among the most used shape memory alloys within a wide range of applications in industry, military technologies, health care, etc. ${ }^{6}$ They are metallic and may be grown by regular microelectronics industry deposition techniques. NiTi-based SMAs can produce as much as $4 \%$ of TWSME strain and recover up to $10 \%$ of the initial deformation. ${ }^{7,8}$ The transformation temperatures can be easily tuned from $250 \mathrm{~K}$ to $1000 \mathrm{~K} .{ }^{6}$ The thermal hysteresis width can be tuned from a few Kelvin up to about $80 \mathrm{~K} .{ }^{10}$ Finally, the TWSME is scalable down to the nanometer scale ${ }^{11}$ and can be triggered at the picosecond scale. ${ }^{12}$

In the present report, we demonstrate that the NiTi alloy can be used to reproducibly switch by $90^{\circ}$ the in-plane uniaxial anisotropy of a $20 \mathrm{~nm}$ thick nickel thin film during the thermal cycle. We first properly quantify NiTi sample longitudinal strain $\left(\varepsilon_{\mathrm{x}}^{\mathrm{NiTi}}\right)$ and transverse strain $\left(\varepsilon_{\mathrm{y}}{ }^{\mathrm{NiTi}}\right)$ produced by an external uniaxial tensile stress followed 
by a thermal cycle, required to setup the TWSME. Second, we characterize magnetic anisotropy of the Ni layer, deposited on top of NiTi after tensile deformation. When NiTi is in its martensite (respectively, austenite) phase, Ni anisotropy points along (respectively, perpendicular to) the initial tensile axis. As the TWSME strain variation of NiTi is tuned from $0 \%$ to $2.7 \%, \mathrm{Ni}$ anisotropy is enhanced in both martensite and austenite phases.

Free-standing $\mathrm{NiTi}$ (composed of 51 at. \% $\mathrm{Ti}$ and 49 at. \% Ni) polycrystalline ribbons are grown by DC magnetron sputtering as described in Ref. 13. Their dimensions are $20 \mu \mathrm{m}$ thick, $3 \mathrm{~cm}$ long, and $0.4 \mathrm{~cm}$ wide. In order to set a two-way shape memory effect, NiTi ribbons must be stretched in the martensite phase and then thermally cycled. ${ }^{8,10}$ First, we stretch them at room temperature (i.e., in the martensite state) under uniaxial tensile stress along the length of the NiTi ribbon. Deformation is performed at $2 \mu \mathrm{m} / \mathrm{s}$ using a commercial Deformation Device System (DDS) by Kammrath \& Weiss Gmbh. During regular tension experiment, elongation of the specimen is measured using a linear displacement gauge equipped in DDS and the corresponding force is recorded. Figure 1(a) shows a typical stressstrain curve measured along the tensile deformation axis, the so-called $\mathrm{x}$ axis in the coordinates defined for this study (see coordinate sys). It is consistent with the expected behavior from the literature. ${ }^{14,15}$ Elastic
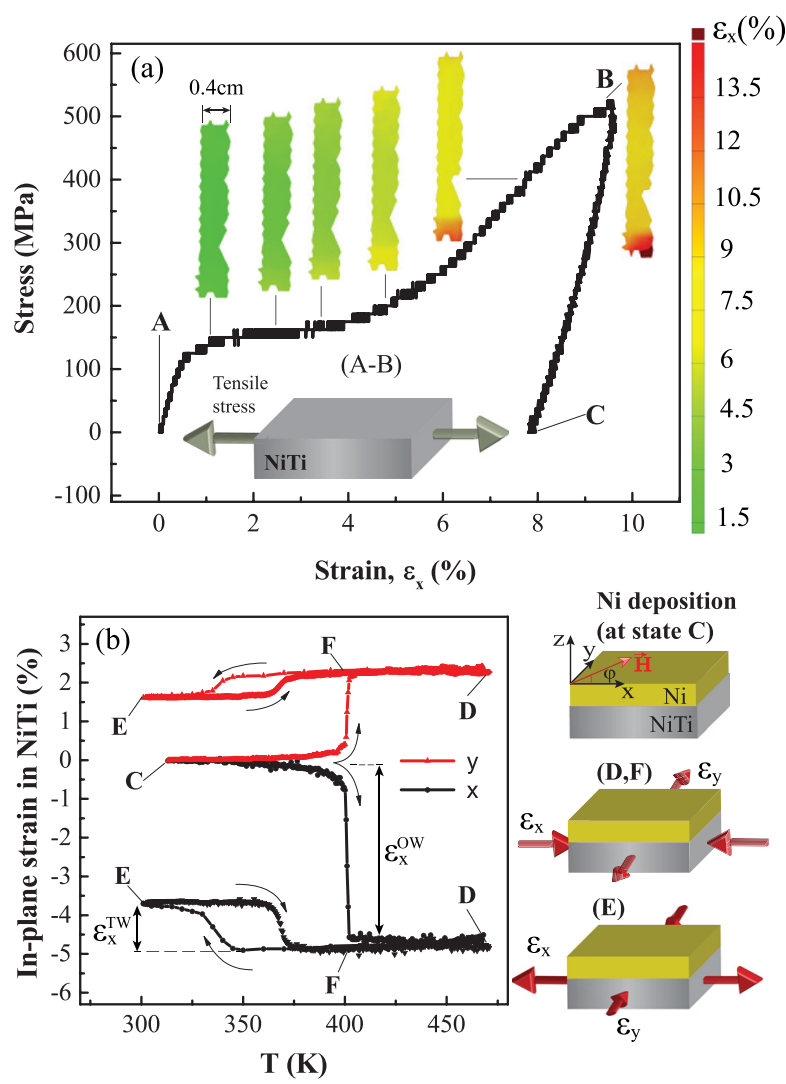

FIG. 1. (a) Stress-strain curve during the tensile deformation of the NiTi substrate. (b) Longitudinal ( $\mathrm{x}$ ) and transversal (y) strains measured by DIC in NiTi during thermal cycles subsequent to tensile deformation. Sketches on the right illustrate the expected in-plane strains in the NiTi/Ni bilayer. deformation $(0 \%-1 \%)$ and then detwinning and martensite reorientation (above $1 \%$ ), along with twin domain nucleation and plastic deformation (above $4 \%$ ), successively happen to accommodate the strain. At point B, corresponding to $9.4 \%$ strain, the sample is unloaded until reaching point $\mathrm{C}$. At that stage, the NiTi ribbon is in its residual deformation state, which is measured with DDS to be equal to $7.8 \%$.

In order to get more precision on the distribution of strain in the NiTi ribbon, we use a digital image correlation (DIC) technique while measuring the stress-strain curve with DDS. The NiTi ribbon is painted with a random black and white pattern. Displacement of the pattern points is analyzed by "ARAMIS 6M" DIC software to locally measure strain. As observed in the inset of Fig. 1(a), distribution of $\varepsilon_{\mathrm{x}}{ }^{\mathrm{NiTi}}$ is negligible over the whole NiTi ribbon length until plastic deformation starts. Strain values measured by DDS and DIC are identical. On the contrary, above 5\%, slight discrepancies occur because of plastic deformations localized at the extremities of NiTi ribbon, close to the area where the sample is clamped in the DDS machine. At maximum applied stress, the DIC strain value in the central region of the ribbon is only $7.3 \%$ instead of the $9.4 \%$ as measured by DDS. The same behavior has been observed for all the samples tested with DIC. We also used the DIC measurement to quantify the compressive strain transversal to the tensile axis $\left(\varepsilon_{\mathrm{y}}{ }^{\mathrm{NiTi}}\right)$. We find a lateral contraction of $-3.3 \%$ at maximum stress (B) and then $-2.8 \%$ after the stress is released (C). For all our measurements, we find the $-\varepsilon_{\mathrm{y}}{ }^{\mathrm{NiTi}} / \varepsilon_{\mathrm{x}}{ }^{\mathrm{NiTi}}$ ratio to range from 0.4 and 0.45 . It is larger than the average Poisson ratio of 0.33 for bulk NiTi. However, our DIC measurements are performed for strain above $1 \%$, i.e., no longer in the elastic regime.

Figure 1(b) shows the variation of NiTi/Ni sample dimensions, along the $\mathrm{x}$ and $\mathrm{y}$ axes, relative to the $\mathrm{C}$ state, as a function of temperature. In order to complete the TWSME preparation, NiTi samples are heated from $\mathrm{C}$ to $\mathrm{D}$ above the austenite transition temperature, then cooled back to $300 \mathrm{~K}$ in the martensite phase (E), and then heated up to $400 \mathrm{~K}$ again to the austenite phase $(\mathrm{F})$. When heating from $\mathrm{C}$ to $\mathrm{D}$, about $4.5 \%$ of loaded strain is recovered along the $\mathrm{x}$ axis by transforming into the austenite phase $\left[\varepsilon_{\mathrm{x}}{ }^{\text {ow }}\right.$ in Fig. $\left.1(\mathrm{~b})\right]$. In $\mathrm{D}$, irrecoverable strain still exists. It is usually accounted for the deformation twins that cannot transform into a single cubic phase of austenite ${ }^{16}$ as well as remaining dislocations and point defects. ${ }^{7}$ Oriented residual microstresses lead to a hysteretic behavior of the strain magnitude as a function of temperature, the so-called TWSME, whose amplitude here is $\Delta \varepsilon_{\mathrm{x}}{ }^{\mathrm{tw}}=+1.3 \%$. Further, thermal sweepings between $300 \mathrm{~K}(\mathrm{E})$ and $400 \mathrm{~K}(\mathrm{~F})$ always produce the same strain hysteresis. DIC measurements confirm that the NiTi sample width is affected in an opposite manner to the length during the thermal process. The sample width expands from $\mathrm{C}$ to $\mathrm{D}$, then contracts from $\mathrm{D}$ to $\mathrm{E}$, and then expands from $\mathrm{E}$ to $\mathrm{F}$ [red curve in Fig. 1(b)]. $\Delta \varepsilon_{\mathrm{y}}{ }^{\mathrm{tw}}$ is $-0.55 \%$ during the TWSME.

We deposit the Ni layer at stage C. Schemes in Fig. 1(b) depict the expected behavior of the NiTi/Ni bilayer during the thermal cycle from $\mathrm{C}$ to F, if Ni undergoes the same strain as NiTi. Such a scenario must lead to a significant change of Ni magnetoelastic anisotropy by the inverse magnetostrictive effect. ${ }^{17}$ A polycrystalline Ni $(20 \mathrm{~nm}) / \mathrm{Pt}$ $(5 \mathrm{~nm})$ stack is deposited on a rotating NiTi free-standing substrate by DC magnetron sputtering at room temperature, with a $10^{-8}$ mTorr base pressure. The deposition rate under 5-6 $\mathrm{mTorr}^{\mathrm{A}}{ }^{+}$is tuned using profilometer measurements and then verified by X-ray reflectivity. $\mathrm{Pt}$ is used as a protective layer against oxidation. Magnetic measurements 
are performed at room temperature using a commercial vibrating sample magnetometer with the ability to rotate the sample holder in the applied magnetic field. The field angle $\varphi$ is defined relative to the tensile strain $\mathrm{x}$ axis as sketched in Fig. 1(b).

Magnetization vs field loop measured immediately after Ni deposition on strained NiTi with $\varepsilon_{\mathrm{x}}{ }^{\mathrm{NiTi}}=5.8 \%$ (similar to Fig. 1) is shown in Fig. 2(a) for the field applied either along the $\mathrm{x}$ direction $\left(\varphi=0^{\circ}\right)$ or along the y direction $\left(\varphi=90^{\circ}\right)$. Both curves look similar. The measurement of remanent magnetization as a function of $\varphi$ shows a small anisotropy along $110^{\circ}$ [Fig. 3(d)]. Its magnitude is always weak, and its direction randomly changes from sample to sample (see also Fig. 3). As the temperature is increased up to the austenite phase (in D or F), much stronger uniaxial anisotropies appear along $\varphi=0^{\circ}$. In Fig. 2(b), it is marked by an easy axis hysteresis loop when the field is applied along $\varphi=0^{\circ}$ and a hard axis loop when the field is applied along $\varphi=90^{\circ}$. This translates in Fig. 3(d) by a typical horizontal peanut shape aligned with the $\mathrm{x}$ axis. On the contrary, when cooled down to $300 \mathrm{~K}(\mathrm{E}), \mathrm{Ni}$ uniaxial anisotropy switches by $90^{\circ}$. In Fig. 2(c), the easy (respectively, hard) axis loop is now measured when the field is applied along $90^{\circ}$ (respectively, $0^{\circ}$ ). In Fig. 3(d), the peanut shape length is now aligned with the $90^{\circ}$ direction. These results fit very well with the scheme in Fig. 1(b). Magnetoelastic uniaxial anisotropy is generated perpendicularly to the tensile strain axis in $\mathrm{Ni}$, whereas it is generated along the compressive strain axis because of the negative magnetostriction of $\mathrm{Ni}^{17,18}$ From stage $\mathrm{C}$ to stage $\mathrm{D}$ as well as from $\mathrm{E}$ to $\mathrm{F}$, the Ni film compresses along the $\mathrm{x}$ axis and expands along the $\mathrm{y}$ axis. As a consequence, a uniaxial anisotropy appears along the $\mathrm{x}$ axis. On the contrary, when cooling the sample from $\mathrm{F}$ to $\mathrm{E}$, the $\mathrm{Ni}$ film expands along the $\mathrm{x}$ axis $\left(\varphi=0^{\circ}\right)$ and contracts along the $\mathrm{y}$ axis. Therefore, a uniaxial anisotropy is observed in the $y$ axis $\left(\varphi=90^{\circ}\right)$. In Fig. 2(d), remanent magnetization $M_{r}$, measured along the $\mathrm{x}$-axis as a
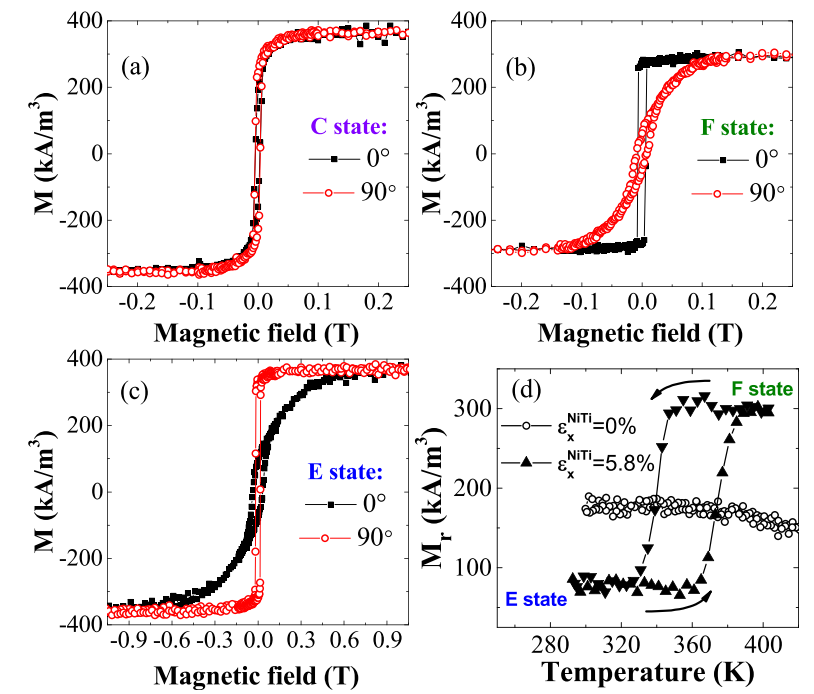

Magnetic field (T)

FIG. 2. (a)-(c) Magnetization vs magnetic field when the field is applied along the $x$-axis $\left(0^{\circ}\right.$, solid square), respectively, y-axis $\left(90^{\circ}\right.$, open circle), when NiTi is in the $\mathrm{C}$ state (a), F state (b), and $\mathrm{E}$ state (c) after being prestrained of $\varepsilon_{\mathrm{x}}{ }^{\mathrm{NiTi}}=5.8 \%$. (d) Remanent magnetization of $\mathrm{NiTi} / \mathrm{Ni}$ along the $\mathrm{x}$-axis as a function of temperature; triangles correspond to the prestretched NiTi substrate and open circle to the nondeformed NiTi substrate.
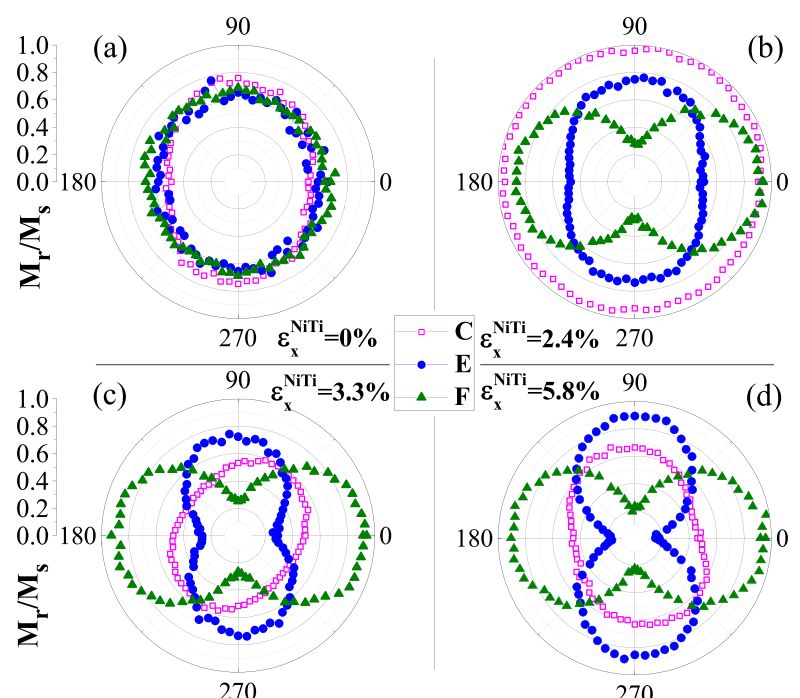

(b)

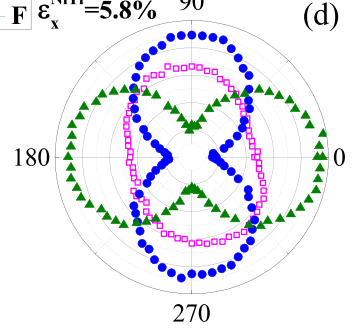

FIG. 3. Normalized remanent magnetization as a function of saturation field angle $\varphi$ for $\mathrm{C}$ (open square), $\mathrm{E}$ (solid circle), and $\mathrm{F}$ states (solid triangle), when NiTi is prestrained to $0 \%$ (a), $2.4 \%$ (b), $3.3 \%$ (c), and $5.8 \%$ (d), respectively.

function of temperature, clearly demonstrates that anisotropy switching happens at the NiTi phase transformation temperatures. The latter prove that the TWSME is responsible for the magnetic anisotropy change, while $\mathrm{M}_{\mathrm{r}}$ of the nonstrained NiTi/Ni does not show any significant changes in temperature.

Nevertheless, when comparing Figs. 2(b) and 2(c), it is counterintuitive that the sample in the $\mathrm{F}$ configuration has five times lower anisotropy field than in the $\mathrm{E}$ configuration although $\Delta \varepsilon_{\mathrm{x}}{ }^{\text {tw }}$ is three times smaller than $\Delta \varepsilon_{\mathrm{x}}{ }^{\text {ow }}$. To get a better understanding, Fig. 3 presents remanent magnetization $\mathrm{M}_{\mathrm{r}}$ vs $\varphi$ polar plots in the case of $\varepsilon_{\mathrm{x}}{ }^{\mathrm{NiTi}}=0 \%$, $2.4 \%, 3.3 \%$, and $5.8 \%$, respectively. When $\mathrm{Ni}$ is deposited on unstressed NiTi [Fig. 3(a)], no uniaxial anisotropy is found in neither E nor F state. As soon as $\mathrm{NiTi}$ is strained prior to $\mathrm{Ni}$ deposition, a clear anisotropy develops in the F state. When $\varepsilon_{\mathrm{x}}{ }^{\mathrm{NiTi}}$ increases, only the valley at $90^{\circ}$ and $180^{\circ}$ gets a little deeper. The total magnetic in-plane uniaxial anisotropy energy $\mathrm{K}$ is extracted from the anisotropy field in hard axis loops. Figure 4 (a) shows that the calculated $\mathrm{K}$ value for $\mathrm{Ni}$ in the $\mathrm{F}$ state increases only from $-1.3 \times 10^{4}$ to $-2.3 \times 10^{4} \mathrm{~J} / \mathrm{m}^{3}$ as $\varepsilon_{\mathrm{x}}{ }^{\mathrm{NiTi}}$ increases from $2.4 \%$ to $7.5 \%$. However, in the $\mathrm{E}$ state, the anisotropy change is much more pronounced as shown in $\mathrm{M}_{\mathrm{r}}$ polar plots in Fig. 3 and Fig. 4(a) where $\mathrm{K}$ in the $\mathrm{E}$ state varies from $2 \times 10^{4}$ up to $1 \times 10^{5} \mathrm{~J} / \mathrm{m}^{3}$. The latest values are much larger than bulk Ni anisotropy $\left(6 \times 10^{3} \mathrm{~J} / \mathrm{m}^{3}\right)$ and among the largest values of strain-induced anisotropy amplitude in polycrystalline Ni reported in the literature. ${ }^{18}$

We can directly translate $\mathrm{Ni}$ anisotropy variation into $\mathrm{Ni}$ strain variation by using the following expression of the magnetoelastic energy: $\mathrm{E}_{\mathrm{ME}}=\mathrm{B} \times\left(\varepsilon_{\mathrm{x}}{ }^{\mathrm{Ni}}-\varepsilon_{\mathrm{y}}{ }^{\mathrm{Ni}}\right)$. B is a magnetoelastic constant for a polycrystalline Ni with uniaxial anisotropy. ${ }^{19,20}$ We use $B=10 \mathrm{MJ} / \mathrm{m}^{3}$ of cubic bulk Ni. In Fig. 4(b), we plot the calculated $\varepsilon_{\mathrm{x}}{ }^{\mathrm{Ni}}-\varepsilon_{\mathrm{y}}{ }^{\mathrm{Ni}}$ in the F state as a function $\varepsilon_{\mathrm{x}}{ }^{\text {ow }}-\varepsilon_{\mathrm{y}}{ }^{\text {ow }}$ and calculated $\varepsilon_{\mathrm{x}}{ }^{\mathrm{Ni}}-\varepsilon_{\mathrm{y}}{ }^{\mathrm{Ni}}$ in the $\mathrm{E}$ state as a function $\varepsilon_{\mathrm{x}}{ }^{\mathrm{tw}}-\varepsilon_{\mathrm{y}}{ }^{\text {tw }}$. Note that $\varepsilon_{\mathrm{x}}{ }^{\text {ow }}-\varepsilon_{\mathrm{y}}{ }^{\text {ow }}$ and $\varepsilon_{\mathrm{x}}{ }^{\mathrm{tw}}-\varepsilon_{\mathrm{y}}{ }^{\mathrm{tw}}$ have been either measured by DIC or extracted from Ref. 8 whose results match ours. $\varepsilon_{\mathrm{x}}{ }^{\mathrm{Ni}}-\varepsilon_{\mathrm{y}}{ }^{\mathrm{Ni}}$ in the F state is 20 times smaller than $\varepsilon_{\mathrm{x}}{ }^{\text {ow }}-\varepsilon_{\mathrm{y}}{ }^{\text {ow }}$. One has to conclude that a structural relaxation occurs in 

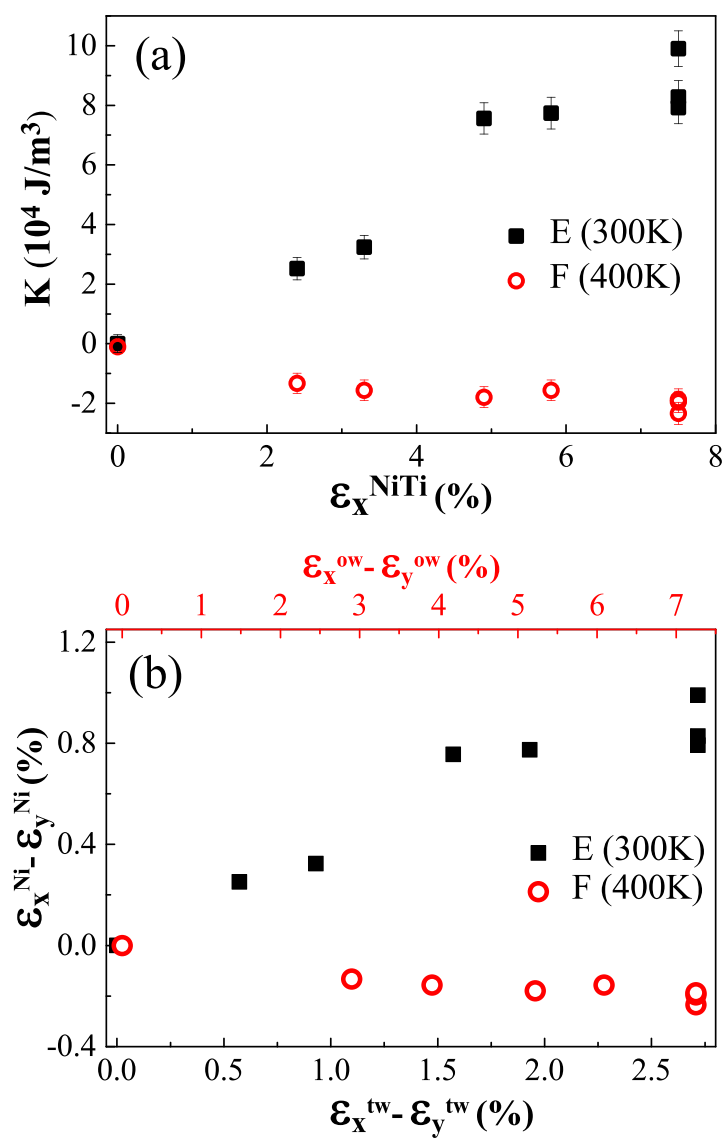

FIG. 4. (a) In-plane anisotropy energy constant $\mathrm{K}$ of $\mathrm{Ni}$ on NiTi in $\mathrm{E}$ (solid square) and $F$ (open circle) states as a function of the prestrain amplitude $\varepsilon_{x}{ }^{\text {NiTi }}$. (b) Ni strain extracted from the variation of anisotropy as a function of the NiTi strain change due to the TWSME from $F$ to $E$.

$\mathrm{Ni}$, while it is heated and strained by $\varepsilon_{\mathrm{x}}{ }^{\text {ow }}-\varepsilon_{\mathrm{y}}{ }^{\text {ow }}$ between stages $\mathrm{C}$ and D. Both bulk recrystallization in $\mathrm{Ni}$ and interface interdiffusion occur even for temperature as low as $450 \mathrm{~K}^{21-24}$ Strong indication of such relaxation is shown in Fig. 3(a) where the slight anisotropy present at stage $\mathrm{C}$ disappears at stage $\mathrm{F}$. We have other samples where a much stronger uniaxial anisotropy disappears from stage $\mathrm{C}$ to $\mathrm{D}$ (not shown here).

In the E state, Ni strain is about a third of the NiTi strain produced by the TWSME when going from $\mathrm{F}$ to $\mathrm{E}$. This ratio is similar to the one found in the NiTiNb $(0.5 \mathrm{~mm}) / \mathrm{FePt}(10-20 \mathrm{~nm})$ bilayer $^{5}$ and in $\mathrm{Ni}$ on a flexible polyethylene naphthalate substrate. ${ }^{18}$ We performed transmission electron microscopy (TEM) to reveal the origin of strain loss at the NiTi/Ni interface and to confirm the amplitude of strain in Ni. Figure 5 shows the dark field STEM image of the full stack NiTi/ $\mathrm{Ni} / \mathrm{Pt}$ in the transverse mode, i.e., we see the cut along the $\mathrm{x}$-axis. All three NiTi, Ni, and Pt layers can be distinguished, but a closer look at the NiTi/Ni interface enlightens a $5-15 \mathrm{~nm}$ thick layer in the NiTi substrate whose crystallinity is different from $\mathrm{NiTi}$ and $\mathrm{Ni}$ ones, including some amorphous regions. Chemical analysis performed by energy dispersive spectroscopy (EDS) reveals that this interfacial layer consists in a Ti-rich oxide whose content in oxygen is maximum at the interface
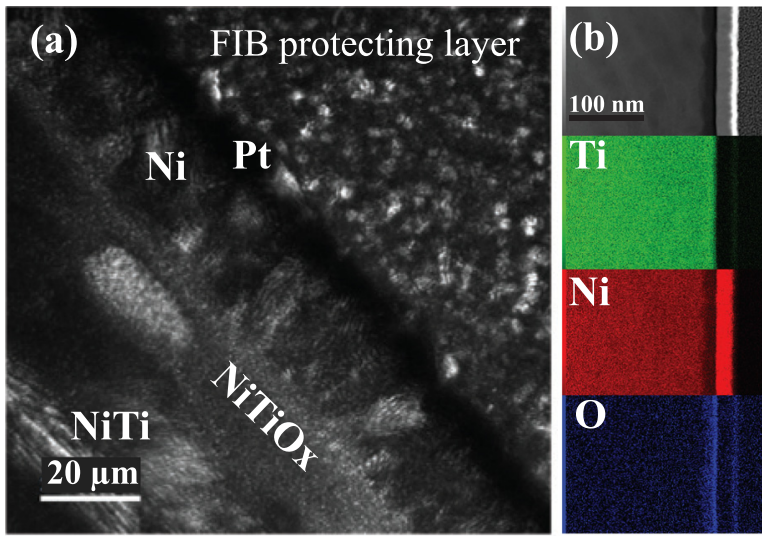

FIG. 5. (a) STEM-HAADF (high-angle annular dark-field imaging) image showing the cross section of the NiTi/Ni/Pt stack at room temperature. (b) Elemental $\mathrm{X}$-mapping from EDS analysis showing separately $\mathrm{Ti}, \mathrm{Ni}$, and $\mathrm{O}$ mapping, which enlightens a zone with excess of Ti and $\mathrm{O}$ at the NiTi/Ni interface.

with $\mathrm{Ni}$ at about $15 \%$ concentration. A similar oxide layer is observed at the surface of our NiTi free-standing substrate, and such surface oxidation is well referenced in the literature. ${ }^{25,26}$ Such a poorly crystallized oxide layer must diminish strain transfer efficiency from NiTi to $\mathrm{Ni}$ during the TWSME. Finally, based on fast Fourier transform (FFT) of STEM images, we can quantify strain in the Ni layer, which is confirmed to be fcc and polycrystalline. For the sample in Fig. 5 where $\mathrm{NiTi}$ is initially was strained up to $7.5 \%$, in-plane strain $\varepsilon_{\mathrm{x}}{ }^{\mathrm{Ni}}-\varepsilon_{\mathrm{y}}{ }^{\mathrm{Ni}}$ ranges from $+0.1 \%$ to $3 \%$ in 9 different regions. This strain was calculated considering the Ni Poisson's ratio to be 0.31 . The $\left\langle\varepsilon_{\mathrm{x}}{ }^{\mathrm{Ni}}-\varepsilon_{\mathrm{y}}{ }^{\mathrm{Ni}}\right\rangle$ average value of $+1.3 \%$ is in agreement with the values extracted from magnetometry in Fig. 4(b).

As a summary, we demonstrated induction of a uniaxial anisotropy, as high as $1 \times 10^{5} \mathrm{~J} / \mathrm{m}^{3}$, in a Ni $(20 \mathrm{~nm})$ thin film deposited on a $20 \mu \mathrm{m}$ thick NiTi shape memory alloy substrate. NiTi deformation due to the two-way shape memory effect (TWSME) produces strain transfer in $\mathrm{Ni}$ and enables us to reproducibly switch $\mathrm{Ni}$ anisotropy by $90^{\circ}$ when going from room temperature to $400 \mathrm{~K}$ and vice versa. About $1 \%$ of strain is transferred in Ni from $2.7 \%$ strain variation during the TWSME. It is a promising result since many parameters such as lattice matching, ferromagnet thickness, NiTi TWSME amplitude, or Ti-rich interfacial oxide can be improved. Finally, the fact that magnetic anisotropy can be tuned to be much lower in the high temperature state (here $400 \mathrm{~K}$ ) than at room temperature makes the shape memory alloy/ferromagnetic bilayer a potential candidate to save write energy in magnetic recording technologies where the media is intrinsically heated during the writing phase.

The authors thank S. Suire, T. Ferte, and C.-S. Chang for help with magnetometry experiments. This work was partially funded by ANRT CIFRE No. 2015/0466 and French PIA project "Lorraine Université d'Excellence" No. ANR-15-IDEX-04-LUE.

\section{REFERENCES}

${ }^{1}$ T. Nozaki, T. Yamamoto, S. Miwa, M. Tsujikawa, M. Shirai, S. Yuasa, and Y. Suzuki, Micromachines 10, 327 (2019).

${ }^{2}$ J. Ma, J. Hu, Z. Li, and C.-W. Nan, Adv. Mater. 23, 1062 (2011). 
${ }^{3}$ G. Radaelli, D. Petti, E. Plekhanov, I. Fina, P. Torelli, B. R. Salles, M. Cantoni, C. Rinaldi, D. Gutiérrez, G. Panaccione, M. Varela, S. Picozzi, J. Fontcuberta, and R. Bertacco, Nat. Commun. 5, 3404 (2014).

${ }^{4}$ C. Feng, D. Hu, K. Gong, X. Jiang, J. Yin, Y. Cao, X.-L. Tang, F. Yang, Z. Zhou, G. Yu, and D. Andrew Evans, Appl. Phys. Lett. 109, 212401 (2016).

${ }^{5}$ C. Feng, J. Zhao, F. Yang, S. Hao, K. Gong, D. Hu, Y. Cao, X. Jiang, Z. Wang, L. Chen, S. Li, L. Sun, L. Cui, and G. Yu, ACS Appl. Mater. Interfaces 8, 7545 (2016).

${ }^{6}$ J. Mohd Jani, M. Leary, A. Subic, and M. A. Gibson, Mater. Des. (1980-2015) 56, 1078 (2014).

${ }^{7}$ O. Benafan, S. A. Padula, R. D. Noebe, T. A. Sisneros, and R. Vaidyanathan, J. Appl. Phys. 112, 093510 (2012).

${ }^{8}$ Y. Liu, Y. Liu, and J. Van Humbeeck, Acta Mater. 47, 199 (1998).

${ }^{9}$ H. Hou, R. F. Hamilton, and M. W. Horn, J. Vac. Sci. Technol., A 34, 050602 (2016).

${ }^{10}$ E. Patoor, D. C. Lagoudas, P. B. Entchev, L. C. Brinson, and X. Gao, Mech. Mater. 38, 391 (2006).

${ }^{11}$ C.-Y. Nien, H.-K. Wang, C.-H. Chen, S. Ii, S.-K. Wu, and C.-H. Hsueh, J. Mater. Res. 29, 2717 (2014).

${ }^{12}$ M. Zhang, G. Cao, H. Tian, S. Sun, Z. Li, X. Li, C. Guo, Z. Li, H. Yang, and J. Li, Phys. Rev. B 96, 174203 (2017).

${ }^{13}$ R. Lima de Miranda, C. Zamponi, and E. Quandt, Adv. Eng. Mater. 15, 66 (2013).
${ }^{14}$ A. P. Stebner, S. C. Vogel, R. D. Noebe, T. A. Sisneros, B. Clausen, D. W. Brown, A. Garg, and L. C. Brinson, J. Mech. Phys. Solids 61, 2302 (2013).

${ }^{15}$ P. Chowdhury and H. Sehitoglu, Prog. Mater. Sci. 88, 49 (2017).

${ }^{16}$ J. X. Zhang, M. Sato, and A. Ishida, Acta Mater. 54, 1185 (2006)

${ }^{17}$ L. Callegaro and E. Puppin, Appl. Phys. Lett. 68, 1279 (1996).

${ }^{18}$ R. Asai, S. Ota, T. Namazu, T. Takenobu, T. Koyama, and D. Chiba, J. Appl. Phys. 120, 083906 (2016).

${ }^{19}$ B. D. Cullity, Introduction to Magnetic Materials (Addison-Wesley Publishing Co., Reading, MA, 1972).

${ }^{20}$ D. Sander, Rep. Prog. Phys. 62, 809 (1999).

${ }^{21}$ Y. G. Krasnoperova, M. V. Degtyarev, L. M. Voronova, and T. I. Chashchukhina, Phys. Met. Metallogr. 117, 267 (2016).

${ }^{22}$ H. Aboulfadl, F. Seifried, M. Stüber, and F. Mücklich, Mater. Lett. 236, 92 (2019).

${ }^{23}$ A. S. Dzhumaliev, Y. V. Nikulin, and Y. A. Filimonov, J. Commun. Technol. Electron. 57, 498 (2012).

${ }^{24}$ P. Bhatt, S. M. Chaudhari, and M. Fahlman, J. Phys.: Condens. Matter 19, 376210 (2007).

${ }^{25}$ B. G. Priyadarshini, S. Aich, and M. Chakraborty, Thin Solid Films 616, 733 (2016).

${ }^{26}$ S. Shabalovskaya, J. Anderegg, and J. Van Humbeeck, Acta Biomater. 4, 447 (2008). 